\title{
Laminarin protects against hydrogen peroxide-induced oxidative damage in MRC-5 cells possibly via regulating NRF2
}

\author{
Xue Liu ${ }^{1}{ }^{,}$Huaman Liu ${ }^{2}$, Yan Li $^{3}{ }^{,}$Xue Zhu ${ }^{4}$, Wei Zhang ${ }^{\text {Corresp. } 4}$ \\ ${ }^{1}$ College of Traditional Chinese Medicine, Shandong University of Traditional Chinese Medicine, Jinan, China \\ 2 Department of Respiration, Affiliated Hospital of Shandong University of Traditional Chinese Medicine, Jinan, China \\ 3 Department of Nursing, Zibo Central Hospital, Zibo, China \\ 4 Department of Respiration, Affiliated Hospital of Shandong University of Traditional Chinese Medicine, Jinan, China \\ Corresponding Author: Wei Zhang \\ Email address: huxizhijia@126.com
}

\section{Abstract}

Oxidative damage is a major cause of lung diseases including pulmonary fibrosis. Laminarin is a kind of polysaccharide extracted from brown algae and plays vital roles in various biological processes. However, functions and mechanisms of laminarin in pulmonary oxidative damage are poorly understood. This study aimed at investigating the protective effect of laminarin against pulmonary oxidative damage and underlying mechanisms. Human lung fibroblasts MRC-5 cells were treated with hydrogen peroxide to induce oxidative damage. Laminarin treatment was performed before or after hydrogen peroxide treatment, and then major indexes of oxidative damage, including superoxide dismutase (SOD), malondialdehyde (MDA), reduced glutathione (GSH) and catalase (CAT), were quantified by biochemical assays. The expression of oxidation-related factor, nuclear factor erythroid 2 like 2 (NRF2) was analyzed by qPCR, Western blot and immunofluorescence assay. NRF2 knockdown and overexpression were performed by cell transfection to reveal possible mechanisms. Results showed that laminarin treatment of $0.020 \mathrm{mg} / \mathrm{mL}$ for $24 \mathrm{~h}$, especially the pretreatment, could significantly relieve changes in SOD, MDA, GSH and CAT that were altered by hydrogen peroxide, and promote NRF2 mRNA ( $P<0.001$ ). NRF2 protein was also elevated by laminarin, and nuclear translocation was observed. Factors in NRF2 signaling pathways, including KEAP1, NQO1, GCLC and $\mathrm{HO1}$, were all regulated by laminarin. Roles of NRF2 were tested, suggesting that NRF2 regulated the concentration of SOD, MDA, GSH and CAT, suppressed KEAP1, and promoted NQO1, GCLC and HO1. These findings suggested the protective role of laminarin against pulmonary oxidative damage, which might involve the regulation of NRF2 signaling pathways. This study provided information for the clinical application of laminarin to pulmonary diseases like pulmonary fibrosis. 
1 Laminarin protects against hydrogen peroxide-induced oxidative damage in MRC-5 cells

2 possibly via regulating NRF2

3 Xue Liu ${ }^{1,2 *}$, Huaman $\mathrm{Liu}^{3 *}$, Yan $\mathrm{Li}^{4}$, Xue Zhu ${ }^{3}$, Wei Zhang ${ }^{3}$

4

5 1, College of Traditional Chinese Medicine, Shandong University of Traditional Chinese

6 Medicine, Jinan, China

7 2, Department of Respiration, Shandong Provincial Chest Hospital, Jinan, China

8 3, Department of Respiration, Affiliated Hospital of Shandong University of Traditional Chinese

9 Medicine, Jinan, China

10 4, Department of Nursing, Zibo Central Hospital, Zibo, China

$11 *$ These authors contributed equally to this work.

12

13 Corresponding Author:

14 Wei Zhang

Email address: huxizhijia@126.com 


\section{Abstract}

Oxidative damage is a major cause of lung diseases including pulmonary fibrosis. Laminarin is a kind of polysaccharide extracted from brown algae and plays vital roles in various biological

processes. However, functions and mechanisms of laminarin in pulmonary oxidative damage are poorly understood. This study aimed at investigating the protective effect of laminarin against pulmonary oxidative damage and underlying mechanisms. Human lung fibroblasts MRC-5 cells were treated with hydrogen peroxide to induce oxidative damage. Laminarin treatment was performed before or after hydrogen peroxide treatment, and then major indexes of oxidative damage, including superoxide dismutase (SOD), malondialdehyde (MDA), reduced glutathione (GSH) and catalase (CAT), were quantified by biochemical assays. The expression of oxidationrelated factor, nuclear factor erythroid 2 like 2 (NRF2) was analyzed by qPCR, Western blot and immunofluorescence assay. NRF2 knockdown and overexpression were performed by cell transfection to reveal possible mechanisms. Results showed that laminarin treatment of 0.020 $\mathrm{mg} / \mathrm{mL}$ for $24 \mathrm{~h}$, especially the pretreatment, could significantly relieve changes in SOD, MDA, GSH and CAT that were altered by hydrogen peroxide, and promote NRF2 mRNA $(P<0.001)$. NRF2 protein was also elevated by laminarin, and nuclear translocation was observed. Factors in NRF2 signaling pathways, including KEAP1, NQO1, GCLC and HO1, were all regulated by laminarin. Roles of NRF2 were tested, suggesting that NRF2 regulated the concentration of SOD, MDA, GSH and CAT, suppressed KEAP1, and promoted NQO1, GCLC and HO1. These findings suggested the protective role of laminarin against pulmonary oxidative damage, which might involve the regulation of NRF2 signaling pathways. This study provided information for the clinical application of laminarin to pulmonary diseases like pulmonary fibrosis.

\section{Introduction}

As one of the vital respiratory organs of human, lung plays important roles in gas exchange as well 
54 as excretion, fluid exchange, regulation of acid-base balance and other biological processes. 55 Nevertheless, lung tissue is exposed to the adverse impact from external environment, which calls 56 for a higher capacity of lung to fight against the oxidative damage. Oxides in lung mainly derive 57 from systemic circulation, gas inhalation and pathological processes of the body. For example, the enhancive oxygen consumption during respiratory burst induces the production of several oxides or enzyme like myeloperoxidase, hypochlorous acid and hydrogen peroxide, which oxidize sulfhydryl groups and cause cellular membrane damage (Goraca \& Józefowicz-Okonkwo 2007). Ozone inhalation may lead to inflammation and pulmonary oxidative damage, mediating the activity of factors such as toll-like receptor 4 (Connor et al. 2012; Li et al. 2011). Moreover, cigarette smoke activates the production of nitric oxide, further aggravating pulmonary oxidative damage (Ren et al. 2000; Turanlahti et al. 2000).

Pulmonary oxidative damage may cause severe diseases, such as chronic obstructive pulmonary disease, pulmonary fibrosis, respiratory distress syndrome and even lung cancer (FernandezBustamante \& Repine 2014; Sunnetcioglu et al. 2016). Clinical trials have indicated the positive correlation between pulmonary fibrosis and the level of oxidative stress. Levels of antioxidants, including reduced glutathione (GSH), super dismutase (SOD) and catalase (CAT), were markedly reduced in the lung of IPF patients (Gao et al. 2007). Besides, ROS levels were significantly upregulated in bleomycin-induced pulmonary fibrosis rats (Teixeira et al. 2008). Extensive efforts have been made to discover substances relieving pulmonary oxidative damage. For instance, hydrogen therapy was found possessing the potential of reducing irradiation-induced pulmonary oxidative stress (Terasaki et al. 2011). Angiotensin-(1-7) and nitric oxide synthase inhibitor LNAME showed inhibitive effects on pulmonary oxidative damage in rodents (de Bittencourt Pasquali et al. 2012; Lu et al. 2016). But there remains an urgent need for nontoxic and antioxidant therapies to prevent and remedy pulmonary oxidative damage and pulmonary fibrosis.

Laminarin is a $\beta(1-3)$ polysaccharide extracted from brown algae. With the development of the purification technique, laminarin is showing its application prospects in clinical trials. Some studies have found the application value of laminarin as dietary supplement since laminarin altered 
81 gut microbiota and had hepatoprotective effects (Neyrinck et al. 2007; Nguyen et al. 2016).

Moreover, the anti-cancer function of laminarin has been reported, which indicated that laminarin could induce cancer cell apoptosis and suppress angiogenesis (Hoffman et al. 1996; Ji \& Ji 2014). Further, It has been reported that laminarin acted as antioxidant (Zhou et al. 2009), although mechanism of this effect was not understood. Thus, more information is still necessary to reveal the role of laminarin in pulmonary oxidative damage.

The aim of this study is to investigate the function of laminarin in hydrogen peroxide-induced pulmonary oxidative damage by NRF2/ARE signaling pathway. Human lung fibroblasts MRC-5 cells were treated with hydrogen peroxide to induce oxidative damage. Laminarin pretreatment and aftertreatment was performed, after which major indexes of oxidative damage, including SOD, malondialdehyde (MDA), GSH and CAT, were quantified by biochemical assays. We also tried to elucidate the regulatory mechanism of laminarin in pulmonary oxidative damage through detecting expression changes of nuclear factor erythroid 2 like 2 (NRF2) and key factors in NRF2 signaling pathways. These findings would help to understand the role and functional mechanism of laminarin in controlling pulmonary oxidative damage and diseases such as pulmonary fibrosis.

\section{Materials and methods}

\section{The detection of laminarin antioxidant activity}

The antioxidant activity of laminarin (Sigma-Aldrich, Saint Louis MO, USA) was detected by clearance rate of hydroxyl free radical $(\cdot \mathrm{OH})$ and superoxide radical $\left(\mathrm{O}_{2}^{-\cdot}\right)$. Vitamin $\mathrm{C}(\mathrm{Vc})$ was used for positive control, and $\mathrm{ddH}_{2} \mathrm{O}_{2}$ was used for negative control. The clearance rate of hydroxyl free radical and superoxide radical were detected by Smirnoff's method and Ponti's method respectively (Smirnoff \& Cumbes 1989; Smirnoff et al, 1978). Antioxidants were added to the reaction systems with different concentrations $(0,1,2,4,8$ and $16 \mathrm{mM} ; 0,0.01,0.02,0.04,0.08$, and $0.16 \mathrm{mM}$ ). Optical density (OD) values at $510 \mathrm{~nm}$ and $560 \mathrm{~nm}$ were measured by microplate reader Multiskan Go (Thermo Scientific, USA). The calculation of clearance rate was as follow: Clearance rate $=[(\mathrm{OD}$ of blank control $)-(\mathrm{OD}$ of antioxidants $)] /(\mathrm{OD}$ of blank control $) \times 100 \%$. Cell culture 
108

109

110

111

112

113

114

115

116

117

118

119

120

121

122

123

124

125

126

127

128

129

130

131

132

133

134

Human lung fibroblast cells MRC-5 (American Type Culture Collection, Manassas VA, USA) were cultured in Dulbecco's modified Eagle's medium supplemented with $10 \%$ fetal bovine serum (Gibco, Carlsbad CA, USA). Cells were incubated in humidified atmosphere containing $5 \% \mathrm{CO}_{2}$ at $37^{\circ} \mathrm{C}$ and passaged when the confluence reached about $80 \%$.

\section{Cell transfection}

Cell transfection was performed to knock down and overexpress NRF2. For NRF2 knockdown, MRC-5 cells in the exponential phase were transfected with the specific small interfering RNA (siRNA) designed for NRF2 gene or the negative control siRNA (RiboBio, Guangzhou, China) using Lipofectamine 2000 (Invitrogen, Carlsbad CA, USA) according to the manufacturer's instruction. For NRF2 overexpression, the complete coding sequence of NRF2 mRNA was ligated to pcDNA3.1 overexpression vector (Thermo Scientific, Carlsbad CA, USA) and the correct clone was screened by sequencing. Then the NRF2 recombined vector (pcDNA3.1-NRF2) was transfected to MRC-5 cells in the exponential phase using Lipofectamine 2000, and the blank vector (pcDNA3.1) was transfected as a negative control. Levels of NRF2 mRNA and protein were detected at $48 \mathrm{~h}$ post transfection.

\section{Hydrogen peroxide and laminarin treatment}

Oxidative damage in MRC-5 cells was induced by hydrogen peroxide treatment. Hydrogen peroxide (HepengBio, Shanghai, China) was added to the culture medium of cells with different concentrations $(0,200,400,600,800$ and $1000 \mu \mathrm{M})$ and then the cells were incubated for 6,12 or $24 \mathrm{~h}$. Laminarin was added to the medium to different concentrations at $1 \mathrm{~h}$ before or after the addition of hydrogen peroxide, and after $24 \mathrm{~h}$ of incubation, 3-[4,5-dimethylthiazol-2-yl]-2,5diphenyl tetrazolium bromide (MTT) assay was performed to determine the proper concentration and time of incubation. Cell transfection was performed at $48 \mathrm{~h}$ before the cells were treated by hydrogen peroxide or laminarin.

Real-time quantitative PCR ( $q P C R)$

Total RNA of MRC-5 cells was extracted using TRIzol (Invitrogen, USA) and purified with RNA Purification Kit (Tiangen, Beijing, China). The quality and quantity of RNA was examined by 
135

136

137

138

139

140

141

142

143

144

145

146

147

148

149

150

151

152

153

154

155

156

157

158

159

160

161

agarose gel electrophoresis and NanoDrop 2000 (Thermo Scientific, USA). The complementary DNA (cDNA) was synthesized by ReverAid First Strand cDNA Synthesis Kit (Thermo Scientific, USA) from $1 \mu \mathrm{g}$ RNA for each sample. The expression level of $N R F 2, K E A P 1, N Q O 1, G C L C$ and HO1 was quantified by qPCR, which was conducted on LightCycler 480 (Roche, Switzerland). Each PCR system contained cDNA (20 ng) and specific primers (Table 1) for the target mRNA, and the reaction was catalyzed by SYBR Green I Master (Roche) according to the manufacturer's instruction. The experiment was performed in triplicate. Data were analyzed by $2^{-\Delta \Delta \mathrm{Ct}}$ method with $G A P D H$ as a reference gene.

\section{Western blot}

Total protein, nucleoprotein and cytoplasmic protein of MRC-5 cells were extracted using Radio Immunoprecipitation Assay Buffer (Beyotime, Shanghai, China) and EpiQuik Nuclear Extraction Kit (Epigentek, Farmingdale NY, USA), respectively. Protein samples were quantified by BioRad Protein Assay (Bio-Rad, Hercules CA, USA) and then loaded to sodium dodecyl sulfatepolyacrylamide gel electrophoresis. Protein bands on the gel were then transferred to polyvinylidene fluoride membranes, which were then blocked in 5\% skim milk for $4 \mathrm{~h}$ at room temperature. The membranes were incubated in Tris-buffered saline and Tween 20 (TBST) containing the specific primary antibodies against NRF2, KEAP1, NQO1, GCLC, HO1 and GAPDH (ab89443, ab150654, ab28947, ab55435, ab13248 and ab8245, Abcam, Cambridge, UK) overnight at $4^{\circ} \mathrm{C}$. After washed in TBST for 5 times, the membranes were incubated in horse radish peroxidase-conjugated secondary antibodies (ab6708, Abcam) for $2 \mathrm{~h}$ at room temperature, and then washed again in TBST for 5 times. Protein signals were developed using ECL Plus Western Blotting Substrate (Pierce, Carlsbad CA, USA).

MTT assay

MTT assay was performed to assess viability and inhibition rate of MRC-5 cells post treatment. The cells $\left(5 \times 10^{4} / \mathrm{mL}\right)$ were added to 96 -well plates and incubated at $37^{\circ} \mathrm{C}$ for $24 \mathrm{~h}$. Then the culture medium was replaced by medium containing hydrogen peroxide or laminarin for further incubation. The assay was performed at different time points using MTT Cell Proliferation and 
162

163

164

165

166

167

168

169

170

171

172

173

174

175

176

177

178

179

180

181

182

183

184

185

186

187

188

Cytotoxicity Assay Kit (Beyotime) according to the manufacturer's instruction. OD at $490 \mathrm{~nm}$ was measured by a microplate reader Multiskan Go. Biological experiments were repeated six times. Inhibition rate was calculated as [(OD of untreated group) - (OD of treated group)]/(OD of untreated group) $\times 100 \%$.

Immunofluorescence

NRF2 protein expression and location in MRC-5 cells were detected by immunofluorescence. Cell smears were fixed in 4\% paraformaldehyde overnight and then washed in phosphate-buffered saline (PBS) for three times. The smears were incubated in hydrogen peroxide (3\%) in methyl alcohol for $10 \mathrm{~min}$, goat serum (Beyotime) for $20 \mathrm{~min}$ and the primary antibody for NRF2 for $2 \mathrm{~h}$ at $37^{\circ} \mathrm{C}$ in sequence, with three times of wash in PBS between steps. Then fluorescein isothiocyanate (FITC)-conjugated secondary antibody (ab7064, Abcam) was added to the smears, which were incubated in the dark for $1 \mathrm{~h}$ at $37^{\circ} \mathrm{C}$. After washed in PBS for three times, the smears were counterstained with 4',6-diamidino-2-phenylindole (DAPI, Beyotime) in the dark at room temperature for $5 \mathrm{~min}$. The smears were mounted and observed under a fluorescence microscope (Olympus, Tokyo, Japan).

\section{Biochemical assays}

Cellular SOD, MDA, GSH and CAT concentrations were detected by biochemical methods using commercial kits: SOD Activity Assay Kit (BioVision, Milpitas CA, USA), MDA Detection Kit (Solarbio, Shanghai, China), GSH and GSSG Assay Kit (Beyotime) and Human CAT ELISA Kit (Uscn Life Science Inc., Wuhan, China). Experiments were conducted according the manufacturers' instruction, and detection was performed by a microplate reader (Thermo Scientific).

\section{Statistical analysis}

All the experiments were performed at least in triplicate and results were expressed as mean \pm standard deviation. Data were analyzed by Student's $t$ test and one-way analysis of variance using SPSS 20 (New York NY, USA). Differences with $P<0.05$ were considered to be statistically significant. 
189

190

191

192

193

194

195

196

197

198

199

200

201

202

203

204

205

206

207

208

209

210

211

212

213

214

215

\section{Results}

The antioxidant activity of laminarin

Laminarin was purified from kelp, and it could resist oxidative damage. In order to assess its antioxidant activity, the clearance rate of hydroxyl free radical and superoxide radical was detected. The results shown that the clearance rates were increased following the raise of concentration (Figure S1). It was found that laminarin possessed strong antioxidant activity against hydroxyl free radical, and it had the similar consequence with Vc (Figure S1A). Meanwhile, laminarin also had the ability of scavenging superoxide radical (Figure S1B). According to these results, it could be indicate that laminarin was a good antioxidant, which could clear free radicals effectively.

Laminarin relieves oxidative damage caused by hydrogen peroxide in MRC-5 cells

The therapeutic effects of laminarin were reported in various diseases. In order to assess the functions of laminarin in oxidative damage of human lung fibroblast cells, this study first determined the proper concentration and time of incubation by analyzing cell viability and inhibition rate after MRC-5 cells were treated by hydrogen peroxide or laminarin of different concentrations and different time of incubation. Results showed that hydrogen peroxide concentration over $600 \mu \mathrm{M}$ induced severe inhibition on MRC-5 cell viability when detected by MTT at 6, 12 and $24 \mathrm{~h}$ post treatment $(P<0.01$, Figure $1 \mathrm{~A})$, and all the five concentrations suppressed cell viability when the detection was performed at $24 \mathrm{~h}$ post treatment $(P<0.05)$. The inhibition rate calculated on the basis of these OD values was raised with the increased concentration and incubation time (Figure 1B). Accordingly, hydrogen peroxide concentration of $600 \mu \mathrm{M}$ and treatment for $24 \mathrm{~h}$ were set in the following experiments. After treated with laminarin of different concentrations (Grade 0 to 11 ) for $24 \mathrm{~h}$, cells were applied to MTT assay, which showed that cell viability was decreased with the increased laminarin concentration, and that concentration of more than $0.0390625 \mathrm{mg} / \mathrm{mL}$ significantly impaired cell viability $(P<0.05$, Figure 1C). Also, the inhibition rate was increased with the ascending laminarin concentration (Figure 1D). In order to guarantee cell viability, we chose $0.1953125 \mathrm{mg} / \mathrm{mL}$ as the proper 
216 laminarin concentration in the following experiments.

217 SOD, MDA, GSH and CAT are major indexes that are altered during oxidative damage. In this 218 study, the four indexes were detected after hydrogen peroxide and laminarin treatment. Results 219 showed that SOD, GSH and CAT levels in MRC-5 cells were decreased by hydrogen peroxide 220 (Figure 2A, 2C and 2D), while MDA level was increased (Figure 2B). Laminarin caused diverse 221 changes that SOD, GSH and CAT were up-regulated and MDA down-regulated. Laminarin 222 pretreatment relieved the change caused by hydrogen peroxide, but the effect of laminarin 223 aftertreatment was weaker. Moreover, level changes of the four substances got more obvious with 224 the increasing incubation time. It could be implied from these data that laminarin treatment, especially the pretreatment, might help to attenuate oxidative damage caused by hydrogen peroxide in MRC-5 cells.

\section{$N R F 2$ is involved in the regulation of oxidative damage by laminarin}

228

229

230

231

232

233

234

235

236

237

238

239

240

241

242

Existed research has found evidence that NRF2 may participate in the regulation of oxidative damage, hence we hypothesized that NRF2 was also involved in the regulation of oxidative damage by laminarin in MRC-5 cells. To test the hypothesis, we first detected NRF2 expression in MRC-5 cells after hydrogen peroxide and laminarin treatment. qPCR results showed that no significant change was detected at 1 or $2 \mathrm{~h}$ post treatment. However, NRF2 mRNA was significantly down-regulated by hydrogen peroxide at 6, 12 and $24 \mathrm{~h}$ post treatment compared to Group control $(P<0.01$, Figure 3A), and laminarin significantly increased $N R F 2 \mathrm{mRNA}$ level at the three time points $(P<0.05)$. Laminarin pretreatment obviously relieved the down-regulation of NRF2 mRNA by hydrogen peroxide $(P<0.01)$, but the aftertreatment only had significant effect when detection was conducted at $24 \mathrm{~h}$ post treatment $(P<0.05)$.

NRF2 protein level was also examined. Western blot showed that NRF2 was expressed mainly in cytoplasm (Figure 3B). The cellular level of NRF2 was suppressed by hydrogen peroxide and induced by laminarin. As for the latter, cells pretreated with laminarin induced NRF2 up-regulation in nucleus compared to those only treated with hydrogen peroxide, while laminarin aftertreatment mainly caused the promotion of NRF2 in cytoplasm. The location change of NRF2 protein was 
243 further detected by immunofluorescence (Figure 3C), which indicated that the pretreatment of 244 laminarin could induce NRF2 expression in nucleus in hydrogen peroxide-induced cells, and 245 laminarin aftertreatment could increase cytoplasmic expression of NRF2. Anyway, laminarin 246 could attenuate the down-regulation of NRF2 caused by hydrogen peroxide, but the translocation 247 of NRF2 and the different effects of laminarin pretreatment and aftertreatment required further 248 investigation.

249 Studies have discovered several factors in NRF2 signaling pathways, including kelch-like ECH 250 associated protein 1 (KEAP1), NAD(P)H quinone dehydrogenase 1 (NQO1), glutamate-cysteine 251 ligase catalytic subunit (GCLC) and heme oxygenase 1 (HO1). Hence the mRNA level of the four 252 factors were also quantified by qPCR in this study. Results showed that KEAP1 mRNA was up253 regulated by hydrogen peroxide after 6,12 and $24 \mathrm{~h}$ of treatment $(P<0.05$, Figure $4 \mathrm{~A})$. Laminarin 254 pretreatment significantly relieved the effect of hydrogen peroxide on KEAP1 mRNA at 6, 12 and 255 256

$24 \mathrm{~h}$ post treatment $(P<0.05)$. However, laminarin aftertreatment did not show significant mitigatory effects when the cells were treated for less than $24 \mathrm{~h}$. Also, the effect of laminarin treatment alone was bewildering, which deserved more detailed research. For NQO1, GCLC and HO1 mRNA levels, similar changing patterns were observed at 6,12 and $24 \mathrm{~h}$ post treatment (Figure 4B, 4C and 4D): hydrogen peroxide suppressed $(P<0.01)$, and laminarin promoted mRNA levels of these factors $(P<0.05)$. Besides, laminarin pretreatment greatly attenuated the suppressive effect of hydrogen peroxide on these mRNAs $(P<0.01)$, while laminarin aftertreatment did not show obvious consequences, possibly due to the limited time range of experiments. Based on these data, laminarin could induce the expression of NRF2 and the related factors KEAP1, NQO1, GCLC and HO1, which implied that NRF2 and its pathways might be involved in the mechanism of laminarin in MRC-5 cells.

To get more supportive information for our hypothesis, NRF2 was knocked down and overexpressed to determine whether it participated in the regulation of oxidative damage. After the cells were transfected with NRF2-specific siRNA, NRF2 mRNA level was significantly suppressed, as quantified by qPCR in MRC-5 cells untreated and treated by hydrogen peroxide or 
270 laminarin $(P<0.05$, Figure 5A). Besides, when NRF2 was knocked down, hydrogen peroxide 271 suppressed and laminarin promoted NRF2 mRNA level. NRF2 protein level in cells possessed 272 similar changing patterns (Figure 5B). Cellular concentration of SOD, MDA, GSH and CAT was 273 also quantified after NRF2 was knocked down (Figure 5C) and results showed that NRF2 274 knockdown could inhibit SOD, GSH and CAT levels and promote MDA level, which suggested 275 the involvement of NRF2 in regulating oxidative damage in MRC-5 cells.

276 Expression changes in KEAP1, NQO1, GCLC and HO1 were analyzed when NRF2 was up277 regulated by its overexpression vector pcDNA3.1-NRF2. qPCR results indicated that $N R F 2$ 278 mRNA level was significantly up-regulated by pcDNA3.1-NRF2 in MRC-5 cells with or without 279 laminarin treatment $(P<0.05$, Figure 6A), suggesting the effective NRF2 overexpression. In both 280 laminarin-treated and untreated MRC-5 cells, NRF2 overexpression could suppress KEAP1 281 mRNA and promote $N Q O 1, G C L C$ and $H O 1$ mRNA levels $(P<0.05$, Figure 6B, 6C, 6D and 6E).

282 Besides, laminarin treatment further promoted the effect of NRF2 overexpression on these factors. 283 Similar protein changing patterns of these factors were also observed in Western blot results 284 (Figure 6F). Collectively, NRF2 could regulate KEAP1, NQO1, GCLC and HO1. Together with 285 the abovementioned results, laminarin might elevate NRF2 and related factors, thus attenuating 286 the oxidative damage caused by hydrogen peroxide in MRC-5 cells.

287 Discussion

288 Laminarin has been reported to have protective effects against various diseases. Although existed 289 studies have found the mitigatory role of laminarin in sepsis-induced pulmonary oxidative damage of rats (Cheng et al. 2011), little is known about the underlying mechanisms. This study investigated the role of laminarin in protecting MRC-5 cells against hydrogen peroxide-induced oxidative damage, as well as the possible mechanism regarding the regulation of NRF2. SOD is a kind of antioxidants that catalyzes the conversion from superoxide radicals to hydrogen peroxide, participating in the protection against oxidant-related lung disorders (Kinnula \& Crapo 2003). Increased GSH prevents oxidative damage (Jat et al. 2013; Weisel et al. 2006), and decreased catalase may contribute to oxidative damage (Escribano et al. 2015). Besides, MDA has 
297 long been used as a biomarker for oxidative damage to lipids (Lykkesfeldt 2007). In this study, we 298 tested hydrogen peroxide of different concentration in MRC-5 cells, and found concentration over $299600 \mu \mathrm{M}$ led to significant suppression on cell viability and high inhibition rate at all the time points 300 examined. After treated with hydrogen peroxide $(600 \mu \mathrm{M})$ for $24 \mathrm{~h}$, MRC-5 cells exhibited

301

302

303

304

305

306

307

308

309

310

311

312

313

314

315

316

317

318

319

320

321

322

323

significantly lower SOD, GSH and CAT levels and significant higher MDA level. Together with the previously reported function of SOD, MDA, GSH and CAT in oxidative damage, data in this study suggested that hydrogen peroxide successfully induced oxidative damage in MRC-5 cells. Laminarin treatment in MRC-5 cells had obvious influences of increasing SOD, GSH and CAT levels, and meanwhile suppressing MDA level, implying the protective function of laminarin against oxidative damage. Similar results have been reported in rats of exhaustive exercise, where laminarin reduced oxidative stress as indicated by elevated SOD, GSH and CAT levels and decreased MDA level (Cheng et al. 2012). The effects of laminarin pretreatment and aftertreatment were compared, and results showed that pretreatment had more significant effects on all the four indexes, implying that laminarin might play preventive roles against pulmonary oxidative damage.

Obvious effects of laminarin aftertreatment might be detected if the treatment lasted for more than $24 \mathrm{~h}$. More investigation in vivo would help to verify the speculation.

Based on the above analysis, we further studied the functional mechanism of laminarin. NRF2 is a vital factor defending against chemical and oxidative stress caused by exogenous substances. KEAP1 was reported as an NRF2 repressor that was up-regulated during oxidative stress, thus leading to the inhibition of NRF2 (Kim \& Vaziri 2010; Kobayashi et al. 2006). Results of this study indicated that hydrogen peroxide treatment promoted KEAP1 level and suppressed NRF2. Laminarin up-regulated NRF2 expression, but its influence on KEAP1 was debatable. Moreover, overexpression of NRF2 suppressed KEAP1 expression. One possible explanation of this phenomenon might lie in the mutual regulation between NRF2 and KEAP1. A growing body of literature has proved the existence of NRF2 regulation mechanisms other than the KEAP1-NRF2 signaling pathway (Bryan et al. 2013). Some researchers maintained that increasing NRF2 level would saturate the antioxidant response element (ARE) binding sites in KEAP1, compelling free 
324 NRF2 to translocate to nucleus and activate the transcription of its downstream genes (Zhang 325 2006). This explanation was supported by some data of this study that laminarin pretreatment 326 increased the proportion of nuclear NRF2 protein, which further activate the expression of NQO1, 327 GCLC and HO1. Nonetheless, it was possible that NRF2 was regulated by other factors that might 328 also affect KEAP1 level.

329 The transcription of NQO1, GCLC and HO1 is regulated by various factors including NRF2. 330 Existed research has indicated that induced NQO1 and HO1 levels were accompanied with the 331 accumulation NRF2 in nucleus, thus protecting cells against oxidative damage (Zhang et al. 2008). 332 In sepsis-induced acute lung injury, up-regulation of the NRF2-GCLC signaling pathway was 333 associated with enhancement of GSH and reduction of oxidative damage (Zong \& Zhang 2016). 334 Consistent with former research, this study found the elevated mRNA and protein levels of NQO1, 335 GCLC and HO1 by NRF2 overexpression, suggesting that NRF2 could promote the expression of 336 NRF2 when it stimulated the cell. Then, NRF2 could activate the expression of anti-oxidant 337 enzymes in downstream by NRF2/ARE signaling pathway. Further, laminarin exerted anti338 oxidation, which might further facilitate the remission of oxidative damage. The specific type of 339 interaction should be explored further.

340 The influence of NRF2 on oxidative damage indexes was also examined in order to elucidate the 341 involvement of NRF2 in laminarin functional mechanisms. Biochemical experiments indicated 342 that knockdown of NRF2 could increase MDA concentration and decrease concentration of SOD, 343 GSH and CAT, enhancing the effects of laminarin in MRC-5 cells. Numerous studies have proved 344 the protective role of NRF2 against oxidation in various cell types, keratinocytes (Madduma 345 Hewage et al. 2016; Zheng et al. 2014), pancreatic $\beta$-cells (Dinić et al. 2016), mesenchymal stem 346 cells (Loseva et al. 2012), amongst others, elevating SOD, GSH and CAT cellular concentration. 347 Besides, up-regulation of NRF2 was accompanied with suppressed MDA level during the 348 amelioration of oxidative damage (Xie et al. 2014). Together with the findings of this study, NRF2 349 was a powerful alleviator of oxidative damage, and it was thus reasonable to deduce that the up350 regulation of NRF2 might be one mechanism for elucidating why laminarin attenuated hydrogen 
351

352

353

354

355

356

357

358

359

360

361

362

363

364

365

366

367

368

369

370

371

372

373

374

375

376

377

378

379

380

381

382

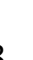

peroxide-induced oxidative damage in MRC-5 cells.

Furthermore, NRF2 also participates in the regulation of oxidative damage that promotes pulmonary fibrosis. The NRF2/ARE signaling pathways activates the expression of many antioxidant enzymes and defense proteins which can subsequently fight against the enhanced oxidative damage during pulmonary fibrosis (Walters et al. 2008). Research in bleomycin-induced pulmonary fibrosis rats has suggested the protective effects of NRF2 signaling pathways, including NQO1 and HO1, on oxidative damage, attenuating pulmonary fibrosis (Ni et al. 2015). In this study, the regulation of laminarin on these signaling pathways of NRF2 might also imply the potential role of laminarin in treating pulmonary fibrosis via attenuating oxidative damage, inspiring us to explore its application on diseases like pulmonary fibrosis.

In summary, this study identified the protective role of laminarin against hydrogen peroxideinduced oxidative damage in MRC-5 cells, which might be related to the regulation of NRF2 and its signaling pathways. These findings facilitated to understand the role of laminarin and the modulation of pulmonary oxidative damage. Further research on more detailed mechanism would be necessary for the clinical application of laminarin to the alleviation of oxidative damage and the treatment of pulmonary fibrosis.

\section{References}

Bryan HK, Olayanju A, Goldring CE, and Park BK. 2013. The Nrf2 cell defence pathway: Keap1-dependent and independent mechanisms of regulation. Biochem Pharmacol 85:705-717.

Cheng D, Liang B, Li M, and Jin M. 2011. Influence of laminarin polysaccahrides on oxidative damage. Int J Biol Macromol 48:63-66.

Cheng D, Liang B, and Li Y. 2012. Protective effect of laminarin polysaccharides on oxidative stress caused by exhaustive exercise. Journal of Medicinal Plants Research 6:1605-1611.

Connor AJ, Laskin JD, and Laskin DL. 2012. Ozone-induced Lung Injury and Sterile Inflammation. Role of Toll-Like Receptor 4. Exp Mol Pathol 92:229-235.

de Bittencourt Pasquali MA, Roberto de Oliveira M, De Bastiani MA, da Rocha RF, Schnorr CE, Gasparotto J, Gelain DP, and Moreira JC. 2012. L-NAME co-treatment prevent oxidative damage in the lung of adult Wistar rats treated with vitamin A supplementation. Cell Biochem Funct 30:256-263.

Dinić S, Grdović N, Uskoković A, Đorđević M, Mihailović M, Jovanović JA, Poznanović G, and Vidaković M. 2016. CXCL12 protects pancreatic $\beta$-cells from oxidative stress by a Nrf2-induced increase in catalase expression 
and activity. Proc Jpn Acad Ser B Phys Biol Sci 92:436-454.

Escribano A, Amor M, Pastor S, Castillo S, Sanz F, Codoñer-Franch P, and Dasí F. 2015. Decreased glutathione and low catalase activity contribute to oxidative stress in children with $\alpha-1$ antitrypsin deficiency. Thorax 70:8283.

Fernandez-Bustamante A, and Repine JE. 2014. Chronic inflammatory diseases and the Acute Respiratory Distress Syndrome (ARDS). Curr Pharm Des 20:1400-1408.

Gao F, Koenitzer JR, Tobolewski JM, Jiang D, Liang J, Nobel PW, and Oury TD. 2007. Extracellular superoxide dismutase inhibits inflammation by preventing oxidative fragmentation of hyaluronan. The Journal of Biological Chemistry 283:6058-6066.

Goraca A, and Józefowicz-Okonkwo G. 2007. Protective effects of early treatment with lipoic acid in LPS-induced lung injury in rats. $J$ Physiol Pharmacol 58:541-549.

Hoffman R, Paper DH, Donaldson J, and Vogl H. 1996. Inhibition of angiogenesis and murine tumour growth by laminarin sulphate. Br J Cancer 73:1183-1186.

Jat D, Parihar P, Kothari SC, and Parihar MS. 2013. Curcumin reduces oxidative damage by increasing reduced glutathione and preventing membrane permeability transition in isolated brain mitochondria. Cell Mol Biol (Noisy-le-grand) 59:1899-1905.

Ji C, and Ji Y. 2014. Laminarin-induced apoptosis in human colon cancer LoVo cells. Oncol Lett 7:1728-1732.

Kim HJ, and Vaziri ND. 2010. Contribution of impaired Nrf2-Keap1 pathway to oxidative stress and inflammation in chronic renal failure. Am J Physiol Renal Physiol 298:F662-671.

Kinnula VL, and Crapo JD. 2003. Superoxide dismutases in the lung and human lung diseases. Am J Respir Crit Care Med 167:1600-1619.

Kobayashi A, Kang M, Watai Y, Tong KI, Shibata T, Uchida K, and Yamamoto M. 2006. Oxidative and Electrophilic Stresses Activate Nrf2 through Inhibition of Ubiquitination Activity of Keap1. Mol Cell Biol 26:221-229.

Li Z, Potts-Kant EN, Garantziotis S, Foster WM, and Hollingsworth JW. 2011. Hyaluronan signaling during ozoneinduced lung injury requires TLR4, MyD88, and TIRAP. PLoS ONE 6:e27137.

Loseva P, Kostyuk S, Malinovskaya E, Clement N, Dechesne CA, Dani C, Smirnova T, Glebova K, Baidakova G, Baranova A, Izhevskaia V, Ginter E, and Veiko N. 2012. Extracellular DNA oxidation stimulates activation of NRF2 and reduces the production of ROS in human mesenchymal stem cells. Expert Opin Biol Ther 12:S85-97.

Lu W, Kang J, Hu K, Tang S, Zhou X, Yu S, Li Y, and Xu L. 2016. Angiotensin-(1-7) inhibits inflammation and oxidative stress to relieve lung injury induced by chronic intermittent hypoxia in rats. Braz J Med Biol Res 49:e5431.

Lykkesfeldt J. 2007. Malondialdehyde as biomarker of oxidative damage to lipids caused by smoking. Clin Chim Acta 380:50-58.

Madduma Hewage SR, Piao MJ, Kang KA, Ryu YS, Fernando PM, Oh MC, Park JE, Shilnikova K, Moon YJ, Shin DO, and Hyun JW. 2016. Galangin Activates the ERK/AKT-Driven Nrf2 Signaling Pathway to Increase the Level of Reduced Glutathione in Human Keratinocytes. Biomol Ther (Seoul). 112:1-8.

Neyrinck AM, Mouson A, and Delzenne NM. 2007. Dietary supplementation with laminarin, a fermentable marine beta (1-3) glucan, protects against hepatotoxicity induced by LPS in rat by modulating immune response in the hepatic tissue. International Immunopharmacology 7:1497-1506.

Nguyen SG, Kim J, Guevarra RB, Lee JH, Kim E, Kim SI, and Unno T. 2016. Laminarin favorably modulates gut 
microbiota in mice fed a high-fat diet. Food Funct 7:4193-4201.

Ni S, Wang D, Qiu X, Pang L, Song Z, and Guo K. 2015. Bone marrow mesenchymal stem cells protect against bleomycin-induced pulmonary fibrosis in rat by activating Nrf2 signaling. Int J Clin Exp Pathol 8:77527761.

Ponti V, Dianzani MU, Cheeseman K, Slater TF. 1978. Studies on the reduction of nitroblue tetrazolium chloride mediated through the action of NADH and phenazine methosulphate. Chem Biol Interact 23:281-291.

Ren G, Zhao M, Fang Q, Yao X, Wang PH, and Tang C. 2000. Injury of cigarette smoke extract and its effect on production of nitric oxide in rat lung tissue. Basic Medicalences \& Clinics 20:44-47.

Smirnoff N, Cumbes QJ. 1989. Hydroxyl radical scavenging activity of compatible solutes. Phytochemistry 28:10571060.

Sunnetcioglu A, Alp HH, Sertogullarından B, Balaharoglu R, and Gunbatar H. 2016. Evaluation of Oxidative Damage and Antioxidant Mechanisms in COPD, Lung Cancer, and Obstructive Sleep Apnea Syndrome. Respir Care 61:205-211.

Teixeira KC, Soares FS, Rocha LG, Silveira PC, Silva LA, Valença SS, Dal Pizzol F, Streck EL, and Pinho RA. 2008. Attenuation of bleomycin-induced lung injury and oxidative stress by $\mathrm{N}$-acetylcysteine plus deferoxamine. Pulm Pharmacol Ther 21:309-316.

Terasaki Y, Ohsawa I, Terasaki M, Takahashi M, Kunugi S, Dedong K, Urushiyama H, Amenomori S, KanekoTogashi M, Kuwahara N, Ishikawa A, Kamimura N, Ohta S, and Fukuda Y. 2011. Hydrogen therapy attenuates irradiation-induced lung damage by reducing oxidative stress. Am J Physiol Lung Cell Mol Physiol 301:L415-426.

Turanlahti M, Pesonen E, Lassus P, and Andersson S. 2000. Nitric oxide and hyperoxia in oxidative lung injury. Acta Paediatr 89:966-970.

Walters DM, Cho HY, and Kleeberger SR. 2008. Oxidative stress and antioxidants in the pathogenesis of pulmonary fibrosis: a potential role for Nrf2. Antioxid Redox Signal 10:321-332.

Weisel T, Baum M, Eisenbrand G, Dietrich H, Will F, Stockis JP, Kulling S, Rüfer C, Johannes C, and Janzowski C. 2006. An anthocyanin/polyphenolic-rich fruit juice reduces oxidative DNA damage and increases glutathione level in healthy probands. Biotechnol J 1:388-397.

Xie Y, Zhao QY, Li HY, Zhou X, Liu Y, and Zhang H. 2014. Curcumin ameliorates cognitive deficits heavy ion irradiation-induced learning and memory deficits through enhancing of Nrf2 antioxidant signaling pathways. Pharmacol Biochem Behav 126:181-186.

Zhang DD. 2006. Mechanistic studies of the Nrf2-Keap1 signaling pathway. Drug Metab Rev 38:769-789.

Zhang Y, Guan L, Wang X, Wen T, Xing J, and Zhao J. 2008. Protection of chlorophyllin against oxidative damage by inducing HO-1 and NQO1 expression mediated by PI3K/Akt and Nrf2. Free Radic Res 42:362-371.

Zheng J, Piao MJ, Kim KC, Yao CW, Cha JW, and Hyun JW. 2014. Fucoxanthin enhances the level of reduced glutathione via the Nrf2-mediated pathway in human keratinocytes. Mar Drugs 12:4214-4230.

Zhou J, Wu H, Liu Q, and Jie M. 2009. Study on antioxidative activity of laminarin in vitro. J Guangdong Pharm Univ 25(4):397-400.

Zong Y, and Zhang H. 2017. Amentoflavone prevents sepsis-associated acute lung injury through Nrf2-GCLcmediated upregulation of glutathione. Acta Biochim Pol 64(1):93-88. 
464

465

466

467

468

469

470

471

472

473

474

475

476

477

478

479

480

481

482

483

484

485

486

487

488

489

490

\section{Legends}

Table 1 Primers used in real-time quantitative PCR (qPCR).

Figure 1 Change of viability and inhibition rate of human lung fibroblast cells MRC-5 by hydrogen peroxide $\left(\mathrm{H}_{2} \mathrm{O}_{2}\right)$ and laminarin of different concentrations and incubation time. (A) MRC-5 cells were treated with $\mathrm{H}_{2} \mathrm{O}_{2}(0,200,400,600,800$ or $1000 \mu \mathrm{M})$ for 6,12 or $24 \mathrm{~h}$, after which optical density (OD) at $490 \mathrm{~nm}$ was measured in MTT assay to assess cell viability. (B) Inhibition rate by $\mathrm{H}_{2} \mathrm{O}_{2}$ calculated according to MTT results. (C) MRC-5 cells were treated with laminarin of different concentrations (grade 0 to 11 ) for $24 \mathrm{~h}$, after which MTT assay was performed to measure OD $490 \mathrm{~nm}$. (D) Inhibition rate by laminarin calculated according to MTT results. ${ }^{*} P<0.05, * * P<0.01$ and $* * * P<0.001$ compared with concentration Grade 1 .

Figure 2 Laminarin relieves the level change of superoxide dismutase (SOD), malondialdehyde (MDA), reduced glutathione (GSH) and catalase (CAT) caused by hydrogen peroxide $\left(\mathrm{H}_{2} \mathrm{O}_{2}\right)$ in MRC-5 cells. MRC-5 cells were treated with $\mathrm{H}_{2} \mathrm{O}_{2}(600 \mu \mathrm{M})$ or laminarin $(0.020 \mathrm{mg} / \mathrm{mL})$, and biochemical detection for SOD (A), MDA (B), GSH (C) and CAT (D) was performed at $0,1,2,6,12$ and $24 \mathrm{~h}$ post treatment. $* * P<0.01$ and $* * * P<0.001$ in comparison between Control Group vs $\mathrm{H}_{2} \mathrm{O}_{2}$ Group. \# $P<0.05$ in comparison between $\mathrm{H}_{2} \mathrm{O}_{2}$ Group and $\mathrm{H}_{2} \mathrm{O}_{2}+$ laminarin Group. $\$ P<0.05, \$ \$ P<0.01$ and $\$ \$ \$ P<0.001$ in comparison between Control Group and laminarin Group. \&\& $P<0.01$ and $\& \& \& P<0.001$ in comparison between $\mathrm{H}_{2} \mathrm{O}_{2}$ Group and laminarin $+\mathrm{H}_{2} \mathrm{O}_{2}$ Group.

Figure 3 Expression change of nuclear factor erythroid 2 like 2 (NRF2) induced by hydrogen peroxide $\left(\mathrm{H}_{2} \mathrm{O}_{2}\right)$ and laminarin in MRC-5 cells. MRC-5 cells were treated with $\mathrm{H}_{2} \mathrm{O}_{2}(600 \mu \mathrm{M})$ and laminarin $(0.020 \mathrm{mg} / \mathrm{mL})$. (A) NRF2 mRNA level quantified by qPCR at 0, 1, 2, 6, 12 and 24 h post treatment. $* * P<0.01$ and $* * * P<0.001$ in comparison between Control Group and $\mathrm{H}_{2} \mathrm{O}_{2}$ Group. \# $P<0.05$ in comparison between $\mathrm{H}_{2} \mathrm{O}_{2}$ Group and $\mathrm{H}_{2} \mathrm{O}_{2}+$ laminarin Group. $\$ P<0.05$, $\$ \$ P<0.01$ and $\$ \$ \$ P<0.001$ in comparison between Control Group and laminarin Group. \&\& $P<0.01$ and $\& \& \& P<0.001$ in comparison between $\mathrm{H}_{2} \mathrm{O}_{2}$ Group and laminarin $+\mathrm{H}_{2} \mathrm{O}_{2}$ Group. (B) NRF2 protein level detected by Western blot at $24 \mathrm{~h}$ post treatment. GAPDH was used as an 
491 internal reference. (C) NRF2 protein expression and located detected by immunofluorescence at $49224 \mathrm{~h}$ post treatment. NRF2 protein (green) was visualized by fluorescein isothiocyanate-conjugated 493 antibodies, and 4',6-diamidino-2-phenylindole (DAPI) was used to dye the nucleus (blue). Bar 494 indicates $10 \mu \mathrm{m}$.

495

496

497

498

499

500

501

502

503

504

505

506

507

508

509

510

511

512

513

514

515

516

517

Figure 4 mRNA level change of KEAP1, NQO1, GCLC and $\mathrm{HO1}$ by $\mathrm{H}_{2} \mathrm{O}_{2}$ and laminarin in MRC-5 cells. Cells were treated with $\mathrm{H}_{2} \mathrm{O}_{2}(600 \mu \mathrm{M})$ and laminarin $(0.020 \mathrm{mg} / \mathrm{mL})$, after which mRNA level of KEAPl (A), NQO1 (B), GCLC (C) and HOl (D) were quantified by qPCR at 0, 1, 2, 6, 12 and 24 h post treatment. $* P<0.05, * * P<0.01$ and $* * * P<0.001$ in comparison between Control Group and $\mathrm{H}_{2} \mathrm{O}_{2}$ Group. \# $P<0.05$ and \#\#\# $P<0.001$ in comparison between $\mathrm{H}_{2} \mathrm{O}_{2}$ Group and $\mathrm{H}_{2} \mathrm{O}_{2}+$ laminarin Group. $\$ P<0.05, \$ \$ P<0.01$ and $\$ \$ \$ P 0.001$ in comparison between Control Group and laminarin Group. \& $P<0.05, \& \& P<0.01$ and $\& \& \& P<0.001$ in comparison between $\mathrm{H}_{2} \mathrm{O}_{2}$ Group and laminarin $+\mathrm{H}_{2} \mathrm{O}_{2}$ Group.

Figure 5 Nuclear factor erythroid 2 like 2 (NRF2) regulates oxidative damage in MRC-5 cells. NRF2 was knocked down by its specific siRNA (siNRF2), and cells were treated with hydrogen peroxide $\left(\mathrm{H}_{2} \mathrm{O}_{2}, 600 \mu \mathrm{M}\right)$ and laminarin $(0.020 \mathrm{mg} / \mathrm{mL})$. Assays were performed at $24 \mathrm{~h}$ post treatment. (A) NRF2 mRNA level quantified by qPCR.. (B) NRF2 protein level detected by Western blot. GAPDH was used as an internal reference. (C) Cellular concentration of superoxide dismutase (SOD), malondialdehyde (MDA), deduced glutathione (GSH) and catalase (CAT) quantified by biochemical assays. Values with different letters indicate statistical significance $(P<$ $0.05)$.

Figure 6 NRF2 regulates KEAP1, NQO1, GCLC and HO1 in MRC-5 cells treated with laminarin. MRC-5 cells were transfected with the overexpression vector of NRF2 (pcDNA3.1NRF2) or blank vector (pcDNA3.1) as a control, and then treated with laminarin $(0.020 \mathrm{mg} / \mathrm{mL})$. qPCR was performed to quantify the mRNA level of $N R F 2$ (A), KEAP1 (B), NQO1 (C), GCLC (D) and $\mathrm{HOl}$ (E) at $24 \mathrm{~h}$ post laminarin treatment.. (F) Protein level of factors detected by Western blot. GAPDH was used as an internal control. Values with different letters indicate statistical significance $(P<0.05)$. 
519 Supplemental Figure Legends

520 Figure S1 The detection of antioxidant activity with different concentrations between

521 laminarin and Vc. (A) The clearance rate of hydroxyl free radical. (B) The clearance rate of 522 superoxide radical. $\mathrm{ddH}_{2} \mathrm{O}_{2}$ was used for negative control. Data are shown as mean $\pm \mathrm{SD}(\mathrm{n}=6)$. * $523 P<0.05, * * P<0.01$ compared with control group. 


\section{Figure 1}

Change of viability and inhibition rate of human lung fibroblast cells MRC- 5 by hydrogen peroxide (H2O2) and laminarin of different concentrations and incubation time.

(A) MRC-5 cells were treated with $\mathrm{H}_{2} \mathrm{O}_{2}(0,200,400,600,800$ or $1000 \mu \mathrm{M})$ for 6,12 or $24 \mathrm{~h}$, after which optical density (OD) at $490 \mathrm{~nm}$ was measured in MTT assay to assess cell viability. (B) Inhibition rate by $\mathrm{H}_{2} \mathrm{O}_{2}$ calculated according to MTT results. (C) MRC-5 cells were treated with laminarin of different concentrations (grade 0 to 11) for $24 \mathrm{~h}$, after which MTT assay was performed to measure OD $490 \mathrm{~nm}$. (D) Inhibition rate by laminarin calculated according to MTT results. $* P<0.05, * * P<0.01$ and $* * * P<0.001$ compared with concentration Grade 1.

A

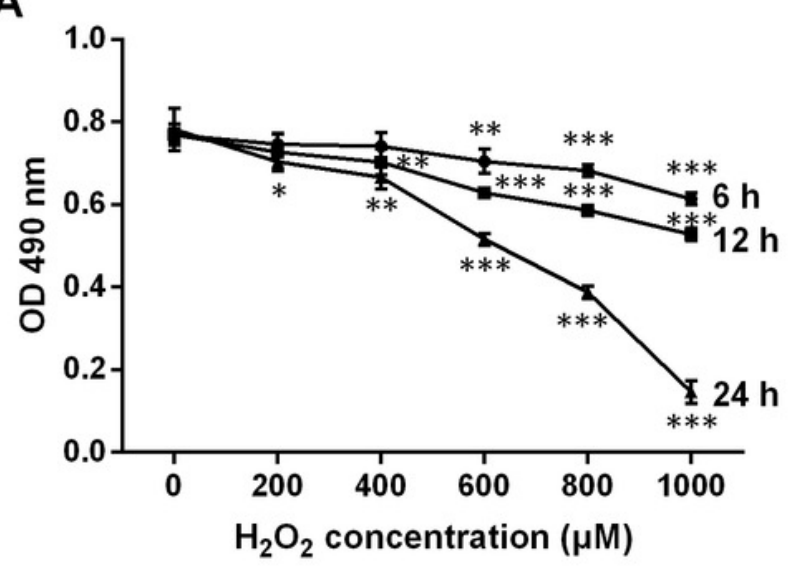

C

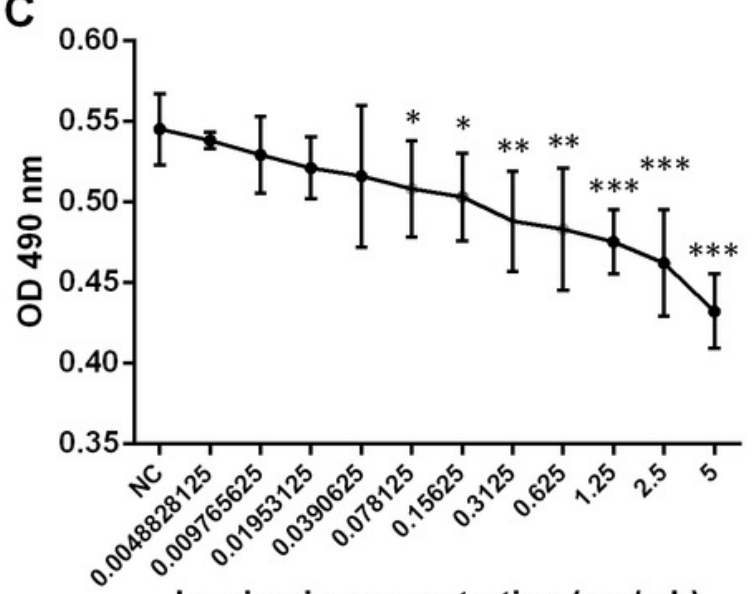

$\frac{\text { Laminarin concentration }(\mathrm{mg} / \mathrm{mL})}{\text { Peer] reviewing PDF | (2017:03:16819:3:0:NEW 10 Jul 2017) }}$
B

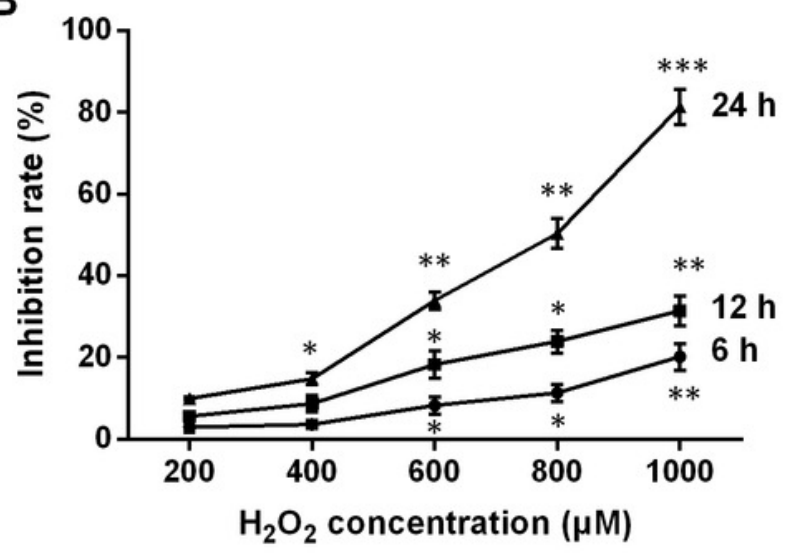

D

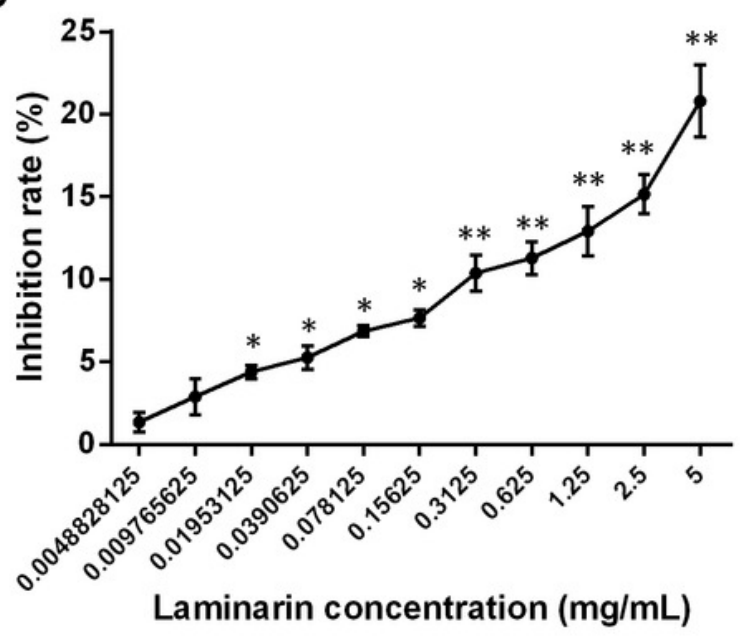




\section{Figure 2}

Laminarin relieves the level change of superoxide dismutase (SOD), malondialdehyde (MDA), reduced glutathione (GSH) and catalase (CAT) caused by hydrogen peroxide (H2O2) in MRC-5 cells.

MRC-5 cells were treated with $\mathrm{H}_{2} \mathrm{O}_{2}(600 \mu \mathrm{M})$ or laminarin $(0.020 \mathrm{mg} / \mathrm{mL})$, and biochemical detection for SOD (A), MDA (B), GSH (C) and CAT (D) was performed at 0, 1, 2, 6, 12 and $24 \mathrm{~h}$ post treatment. ${ }^{* *} P<0.01$ and ${ }^{* * *} P<0.001$ in comparison between Group control and Group $\mathrm{H}_{2} \mathrm{O}_{2}$. $\# P<0.05$ in comparison between Group $\mathrm{H}_{2} \mathrm{O}_{2}$ and Group $\mathrm{H}_{2} \mathrm{O}_{2}+$ laminarin. \$ $P$ $<0.05, \$ \$ P<0.01$ and $\$ \$ \$ P 0.001$ in comparison between Group control and Group laminarin. $\& \& P<0.01$ and $\& \& \& P<0.001$ in comparison between Group $\mathrm{H}_{2} \mathrm{O}_{2}$ and Group laminarin $+\mathrm{H}_{2} \mathrm{O}_{2}$.
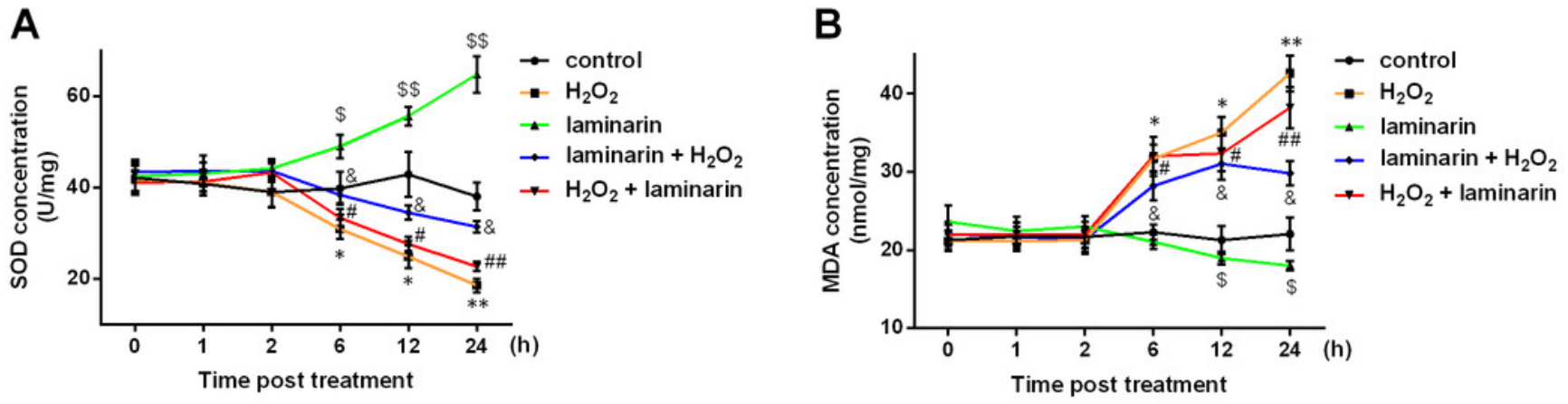

C
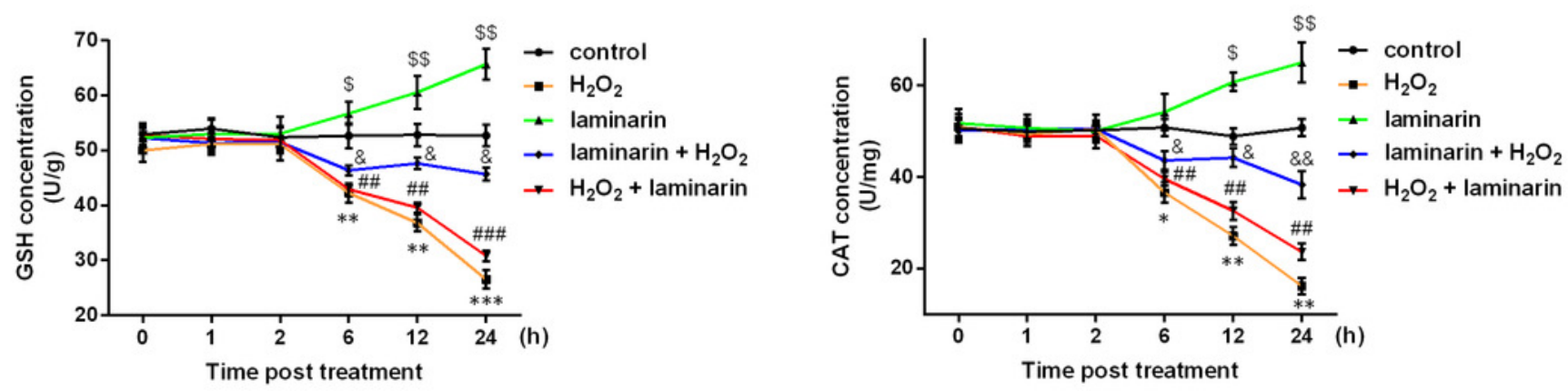


\section{Figure 3}

Expression change of nuclear factor erythroid 2 like 2 (NRF2) induced by hydrogen peroxide (H2O2) and laminarin in MRC-5 cells.

MRC-5 cells were treated with $\mathrm{H} 2 \mathrm{O} 2(600 \mu \mathrm{M})$ and laminarin $(0.020 \mathrm{mg} / \mathrm{mL})$. (A) NRF2 mRNA level quantified by $\mathrm{qPCR}$ at $0,1,2,6,12$ and $24 \mathrm{~h}$ post treatment. $* * \mathrm{P}<0.01$ and $* * * \mathrm{P}<$ 0.001 in comparison between Group control and Group H2O2. \# P<0.05 in comparison between Group H2O2 and Group H2O2 + laminarin. \$ P $<0.05$, \$ $\mathrm{P}<0.01$ and \$\$ $\$ \mathrm{P}<$ 0.001 in comparison between Group control and Group laminarin. $\& \& P<0.01$ and $\& \& \& P<$ 0.001 in comparison between Group H2O2 and Group laminarin + H2O2. (B) NRF2 protein level detected by Western blot at $24 \mathrm{~h}$ post treatment. GAPDH was used as an internal reference. (C) NRF2 protein expression and located detected by immunofluorescence at $24 \mathrm{~h}$ post treatment. NRF2 protein (green) was visualized by fluorescein isothiocyanateconjugated antibodies, and 4',6-diamidino-2-phenylindole (DAPI) was used to dye the nucleus (blue). Bar indicates $10 \mu \mathrm{m}$. 


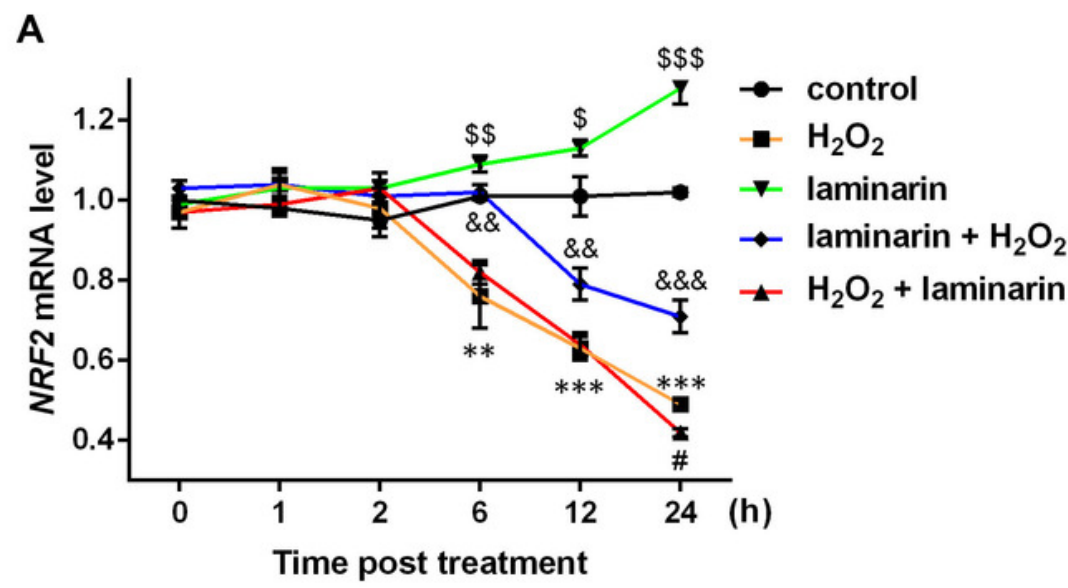

B

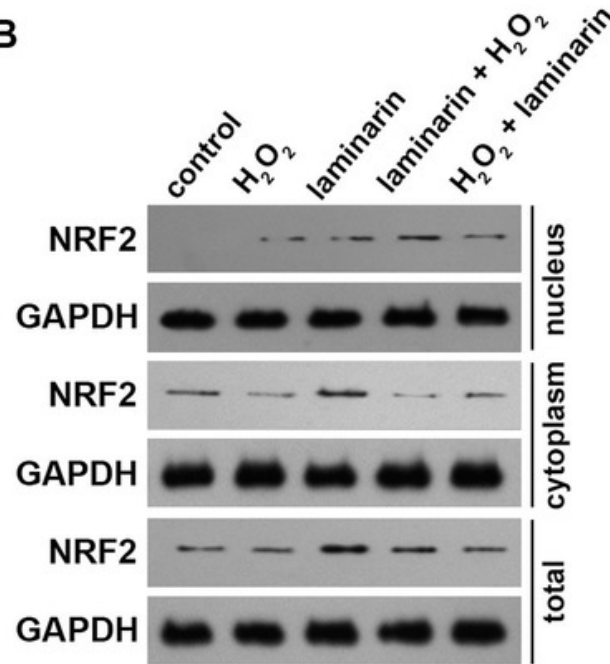

C
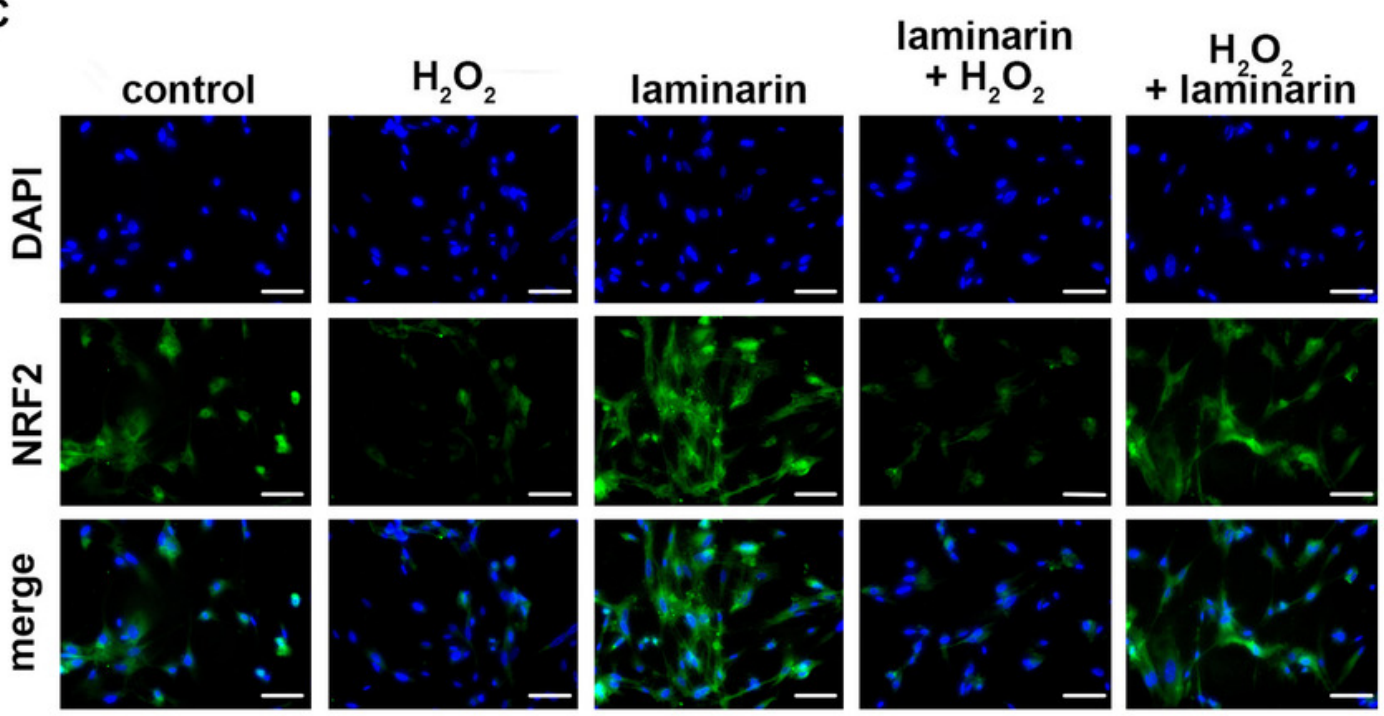


\section{Figure 4}

mRNA level change of KEAP1, NQO1, GCLC and $\mathrm{HO} 1$ by $\mathrm{H} 2 \mathrm{O} 2$ and laminarin in MRC-5 cells.

Cells were treated with $\mathrm{H} 2 \mathrm{O} 2(600 \mu \mathrm{M})$ and laminarin $(0.020 \mathrm{mg} / \mathrm{mL})$, after which $\mathrm{mRNA}$ level of KEAP1 (A), NQO1 (B), GCLC (C) and HO1 (D) were quantified by qPCR at $0,1,2,6,12$ and $24 \mathrm{~h}$ post treatment. $* \mathrm{P}<0.05, * * \mathrm{P}<0.01$ and $* * * \mathrm{P}<0.001$ in comparison between Group control and Group H2O2. \# P $<0.05$ and \#\#\# P $<0.001$ in comparison between Group H2O2 and Group H2O2 + laminarin. \$ P $<0.05, \$$ P $<0.01$ and \$\$ $\$ P<0.001$ in comparison between Group control and Group laminarin. $\& P<0.05, \& \& P<0.01$ and $\& \& \& P<0.001$ in comparison between Group H2O2 and Group laminarin + H2O2.
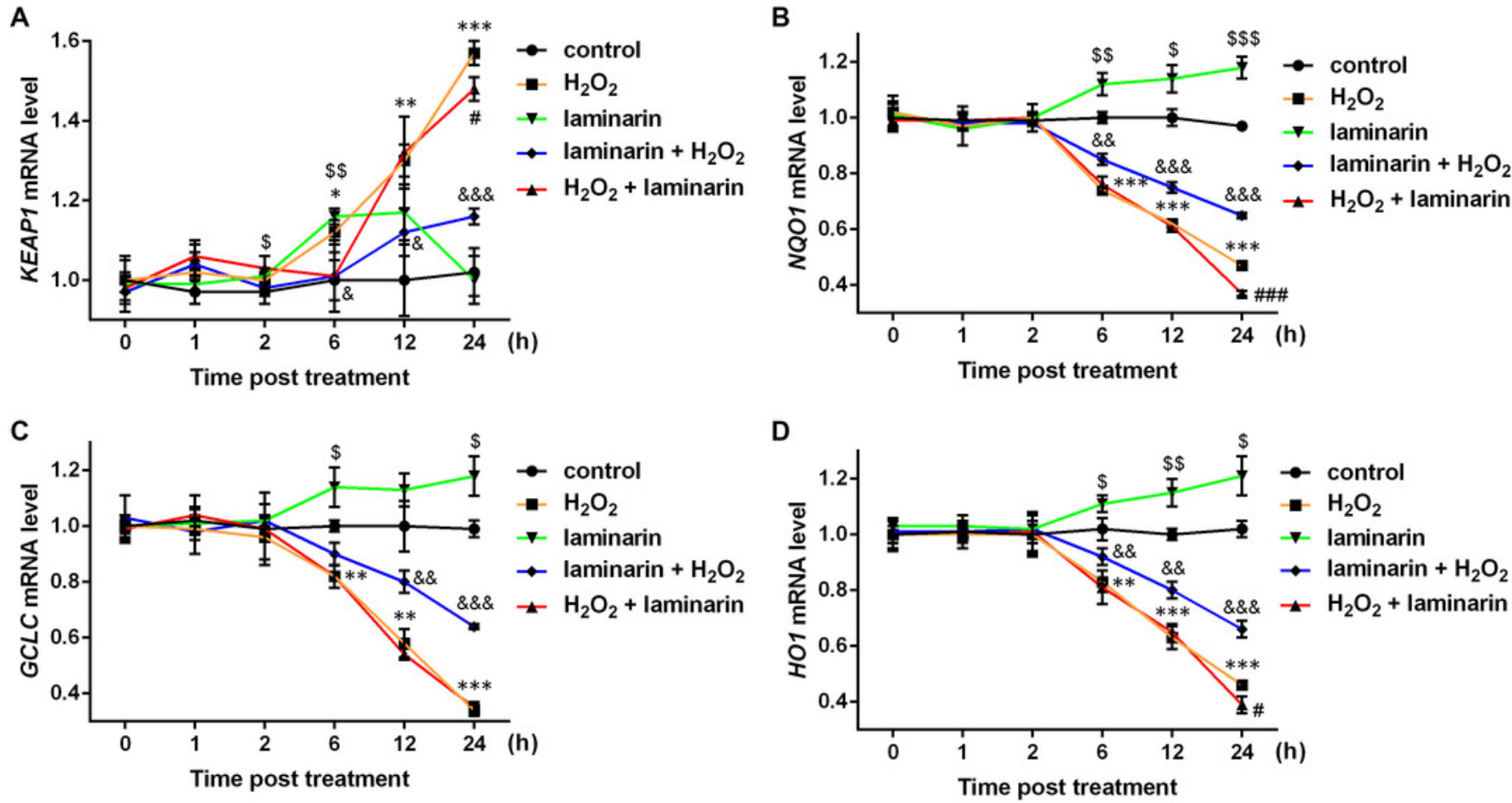


\section{Figure 5}

Nuclear factor erythroid 2 like 2 (NRF2) regulates oxidative damage in MRC-5 cells.

NRF2 was knocked down by its specific siRNA (siNRF2), and cells were treated with hydrogen peroxide $\left(\mathrm{H}_{2} \mathrm{O}_{2}, 600 \mu \mathrm{M}\right)$ and laminarin $(0.020 \mathrm{mg} / \mathrm{mL})$. Assays were performed at $24 \mathrm{~h}$ post treatment. (A) NRF2 mRNA level quantified by qPCR.. (B) NRF2 protein level detected by Western blot. GAPDH was used as an internal reference. (C) Cellular concentration of superoxide dismutase (SOD), malondialdehyde (MDA), deduced glutathione (GSH) and catalase (CAT) quantified by biochemical assays. Values with different letters indicate statistical significance $(P<0.05)$.

A

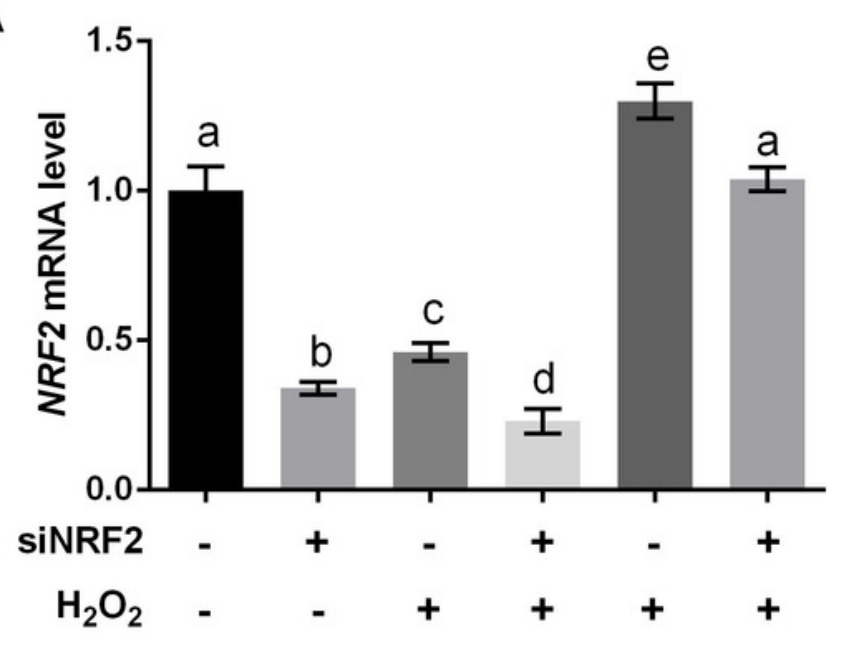

B

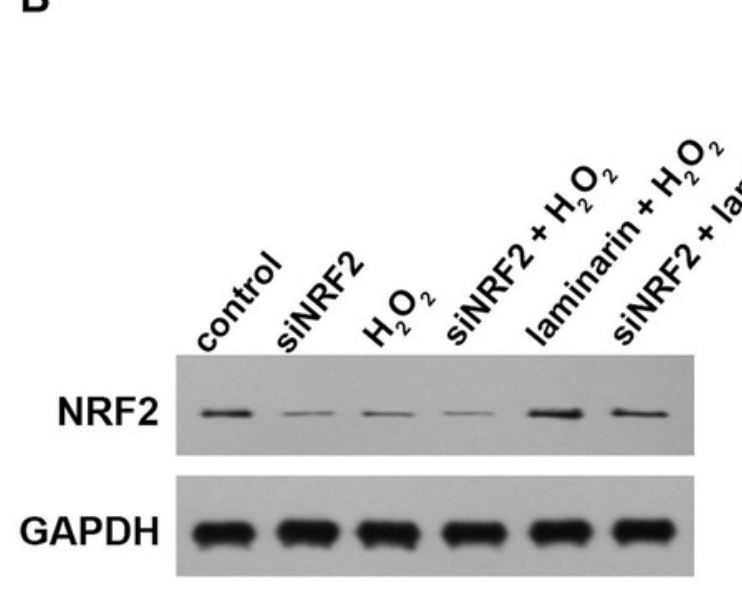

laminarin

C

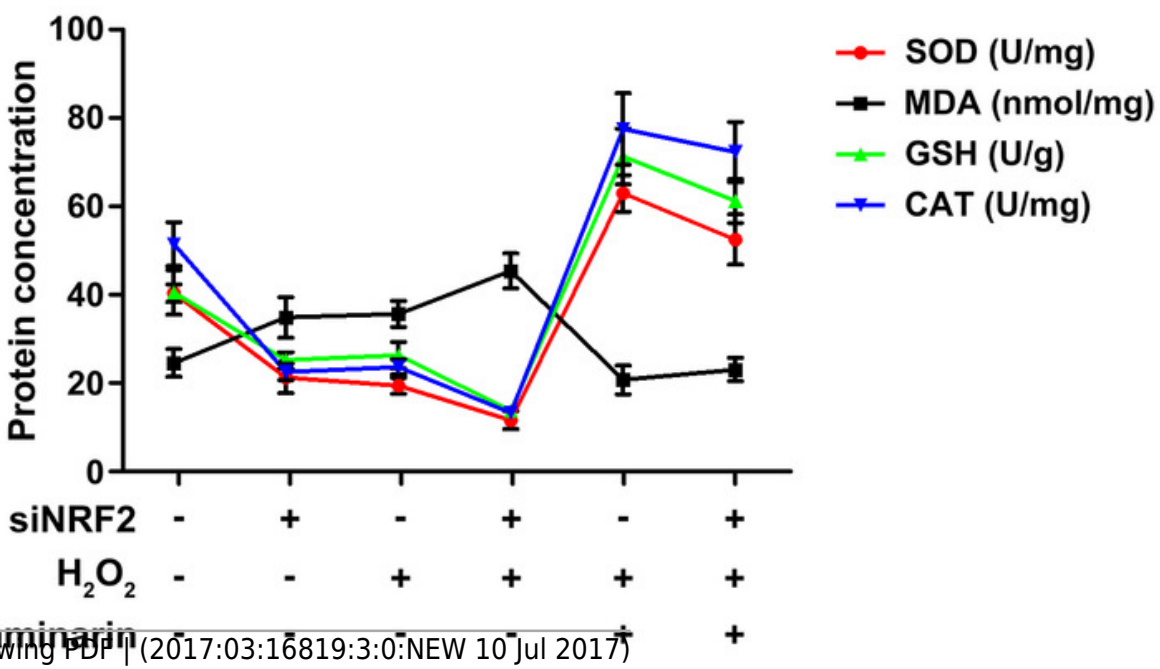




\section{Figure 6}

NRF2 regulates KEAP1, NQO1, GCLC and HO1 in MRC-5 cells treated with laminarin.

MRC-5 cells were transfected with the overexpression vector of NRF2 (pcDNA3.1-NRF2) or blank vector (pcDNA3.1) as a control, and then treated with laminarin $(0.020 \mathrm{mg} / \mathrm{mL})$. qPCR was performed to quantify the mRNA level of NRF2 (A), KEAP1 (B), NQO1 (C), GCLC (D) and HO1 (E) at $24 \mathrm{~h}$ post laminarin treatment.. (F) Protein level of factors detected by Western blot. GAPDH was used as an internal control. Values with different letters indicate statistical significance $(P<0.05)$.
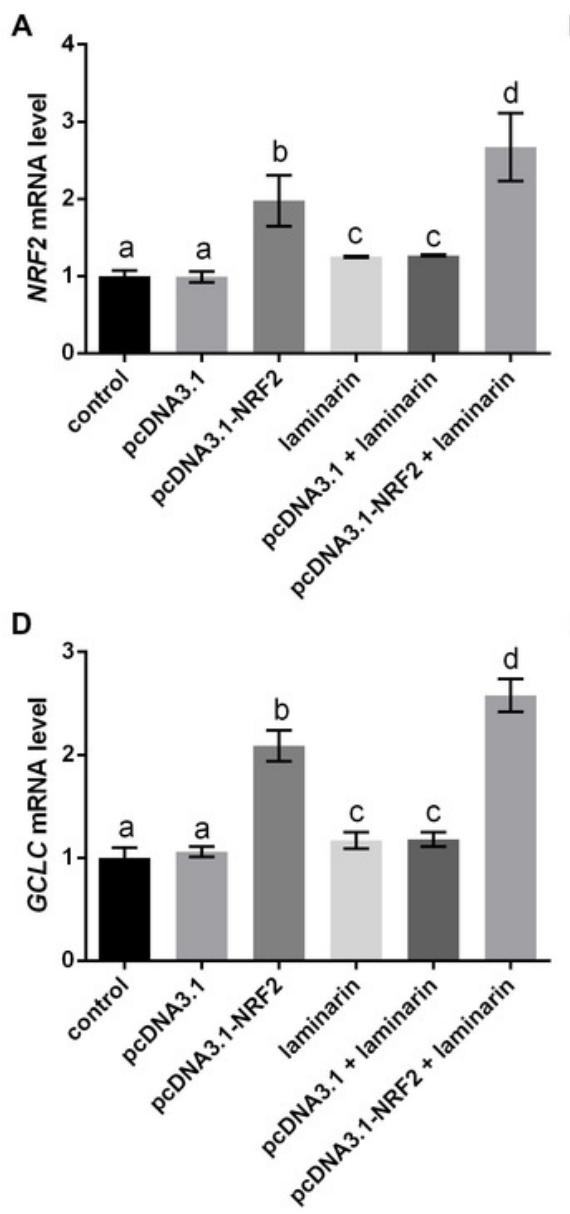

B

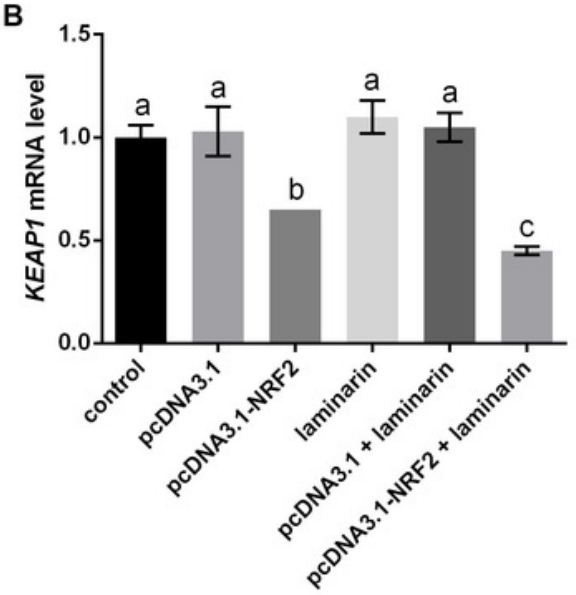

E

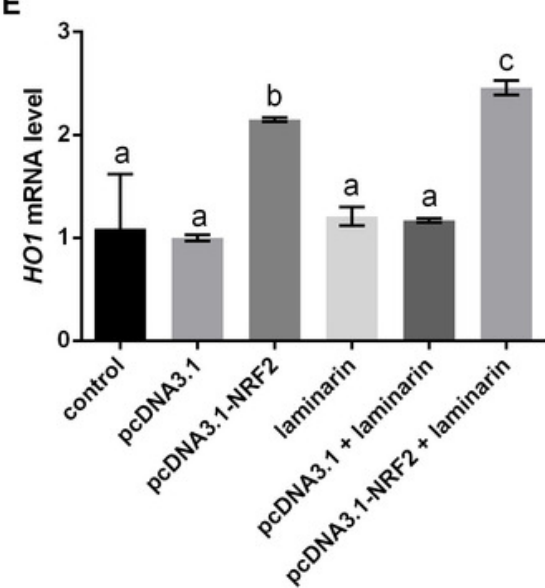

C

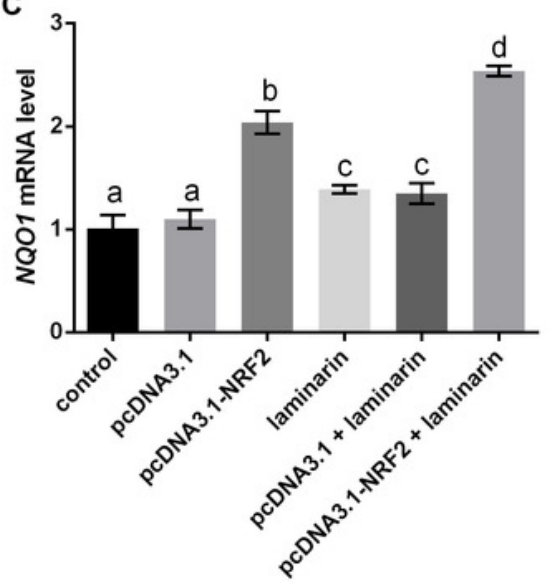

$\mathbf{F}$ 
Table $\mathbf{1}$ (on next page)

Primers used in real-time quantitative PCR (qPCR). 
1 Table 1 Primers used in real-time quantitative PCR (qPCR).

\begin{tabular}{|c|c|c|}
\hline Primer & Sequence $\left(5^{\prime}\right.$ to $\left.3^{\prime}\right)$ & Product size (bp) \\
\hline \multirow{2}{*}{$N R F 2$} & Forward: TCCGGGTGTGTTTGTTCCAA & \multirow{2}{*}{88} \\
\hline & Reverse: CGCCCGCGAGATAAAGAGTT & \\
\hline \multirow{2}{*}{ KEAP1 } & Forward: GTCCCCTACAGCCAAGGTCC & \multirow{2}{*}{175} \\
\hline & Reverse: ACTCAGTGGAGGCGTACATC & \\
\hline \multirow{2}{*}{ NQO1 } & Forward: GGTTTGGAGTCCCTGCCATT & \multirow{2}{*}{134} \\
\hline & Reverse: ACCAGTGGTGATGGAAAGCA & \\
\hline \multirow{2}{*}{ GCLC } & Forward: GAGGTCAAACCCAACCCAGT & \multirow{2}{*}{92} \\
\hline & Reverse: AAGGTACTGAAGCGAGGGTG & \\
\hline \multirow{2}{*}{$\mathrm{HOl}$} & Forward: TCCTGGCTCAGCCTCAAATG & \multirow{2}{*}{108} \\
\hline & Reverse: CGTTAАACACСТСССТСССС & \\
\hline \multirow{2}{*}{ GAPDH } & Forward: ATCTTCTTTTGCGTCGCCA & \multirow{2}{*}{202} \\
\hline & Reverse: TTAAAAGCAGCCCTGGTGACC & \\
\hline
\end{tabular}

